\title{
O APARTHEID NA LITERATURA: A MORTE DE UM FILHO (1996), DE NJABULO NDEBELE
}

\section{APARTHEID IN LITERATURE: DEATH OF A SON (1996), BY NJABULO NDEBELE}

\author{
Samira Corrêa Chaim" \\ Silvio Ruiz Paradiso**
}

Resumo: A discriminação contra as pessoas negras não é um fato esquecido atualmente. O presente artigo analisa a denúncia contra o racismo e o Apartheid na literatura pós-colonial do escritor sul-africano Njabulo Ndebele, com seu conto Death of a son (1996) (A morte de um filho [2007]). Utilizando uma metodologia de pesquisa bibliográfica, sobretudo de cunho pós-colonial, pretende-se apresentar de que forma esse autor expõe as condições da pessoa negra no período ainda envolto pelo regime do Apartheid, sua objetificação e anulação como sujeito, frutos do processo colonial holandês e inglês na África do Sul ocorrido nas primeiras décadas do século XX.

PalaVras-chave: Literatura africana. Pós-colonialismo. Racismo. Apartheid.

AвSTRACT: Discrimination against black people is still an issue of present times. This paper examines reports against racism and the Apartheid in the post-colonial literature of the South African writer Njabulo Ndebele, especially in his short story Death of a son (1996) [2007]. Using a literature research methodology, especially a post-colonial methodology, the paper intends to show how the author presents the conditions black people lived during the Apartheid, their objectification and their annulment as subjects, consequences of the Dutch and English colonial process in Africa South in the early decades of the twentieth century.

KEYwORDS: African literature. Postcolonialism. Racism. Apartheid.

\footnotetext{
"Graduanda pelo Centro Universitário de Maringá (Unicesumar). E-mail: samirachain@hotmail

"* Doutorando em Estudos Literários pela Universidade Estadual de Londrina (UEL). Professor de literaturas em língua Inglesa e Teorias da Literatura da UniCesumar. E-mail: silvinhoparadiso@hotmail.com
} 


\section{CONSIDERAÇÕES INICIAIS}

Racismo é pensar e admitir que existem "raças" superiores e inferiores e expor esses pensamentos na prática, de forma humilhante contra os tidos como inferiores. $\mathrm{O}$ racismo e o Apartheid não estão de fora da literatura, sobretudo nos textos do escritor Njabulo Ndebele, nascido na África do Sul.

Ele é o autor pós-colonialista que passamos a analisar. Refletindo sobre política e arte, escreveu histórias que moveram o povo sul-africano para além dos manifestos e também para uma visão de um povo (negro) que só busca seu lugar na sociedade. Sendo escritor pós-colonialista, aborda os fatos que influenciaram a cultura negra após a Segunda Guerra Mundial e os efeitos deixados pela colonização europeia, principalmente britânica e holandesa na África do Sul.

Como toda colonização é um processo de invasão, divisão e espoliação, com o regime Apartheid não seria diferente. $\mathrm{O}$ Apartheid foi um regime de segregação racial, ou seja, foi uma separação entre brancos e negros que aconteceu na África do Sul. Em 1902, colonizadores brancos instituíram a segregação racial (separação dos grupos raciais) como sistema de domínio, privando a população não branca do seu desenvolvimento e de direitos políticos e civis. Essa dominação dos brancos, que limitou os diretos dos negros, foi definida em lei em 1913, expondo os negros à situação de humilhação dentro das suas próprias terras. Duas leis impediam o desenvolvimento dos negros: "O Ato das Terras" e as "Leis do Passe". A primeira garantia à população branca a maior parte das terras sul-africanas e a maioria negra ficaria com uma pequena parte, privando-os assim do seu desenvolvimento como agricultores autossuficientes. A população negra só poderia entrar na cidade caso tivesse emprego permanente, porém, era necessário deixar sua família na reserva (guetos) e retornar para casa somente quando seus serviços não fossem mais necessários. A segunda lei exigia que todos os negros possuíssem um passaporte, pois, assim, a supremacia branca conseguia movimentar todos os seus passos, até mesmo depois do toque de recolher. Deveriam sempre estar com esse passaporte, pois qualquer pessoa branca teria o direto de pedir para verificação este passaporte; caso o negro não o portasse resultaria na perda do emprego ou até mesmo sua prisão (PAZZINATO, 1997).

Njabulo Ndebele evidencia essa repressão em seu conto Death of a son (1996). Dentre tantos abusos, cita o seguinte: "Tinha acontecido durante o dia, quando os soldados e a polícia que vieram patrulhar a township com seus Casspirs blindados começaram a atirar a esmo pelas ruas" (NDEBELE, 2007, p. 222). Relacionando o conto com o contexto histórico, Pazzinato e Senise (1995, p. 376) apontam a forte repressão policial contra os negros, sendo eles manifestantes ou não; a polícia poderia aplicar choques e maltratar a população não branca até que o governo os detivesse.

Essa repressão contra negros não parou nem começou com o regime Apartheid. Segundo BONNICI (2009, p. 61), "a partir do século XVI ser europeu denotava ser um homem (masculino) branco e partícipe de 
uma sociedade que dominava o planeta". Esses fatores fizeram com que se criasse um conceito de raça superior e, sendo assim, outremizar os povos não brancos para justificar essa pseudossuperioridade. Com o surgimento de uma literatura anglo-africana, constata-se que não somente Ndebele abordava temas como racismo, exclusão e repressão, mas outros autores também evidenciam isso em suas obras literárias. $\mathrm{O}$ que poderia ser chamada de "literatura negra britânica" é um "movimento", verificado a partir de 1950, que registra a zona de contato entre o pós-colonialismo e as culturas britânicas no Reino Unido, produzindo um entremeio no centro literário britânico (BONNICI, 2009, p. 62). Mas foi desde os anos de 1970 que o campo de estudos pós-coloniais ganhou proeminência e, com a desintegração do império europeu depois da Segunda Guerra Mundial, houve grande interesse atual pela literatura e crítica pós-colonial (BONNICI, 2005, p. 21). No entanto, é somente em meados do século XX que acontece uma recuperação da voz dos negros para contribuição literária. Como exemplo de outros textos em que as mesmas situações de racismo aparecem temos Foreigner: Three English Lives, publicado em 2007 por Caryl Phillips.

Tanto Ndebele como Phillips mostram que o personagem negro, mesmo sendo um sujeito diaspórico, carrega sua cultura, entretanto são considerados estranhos em sua própria terra. A hostilidade dos olhares da população branca tira o negro do seu lugar e o marginaliza, deixando clara a divisão colonizador/colonizado; é quando a identi- dade cultural se perde e é erguida uma pirâmide de hierarquização.

O racismo não deixa nenhum espaço de negociação para o outro recuperar a subjetividade, e nem a sociedade ocidental "civilizada", exceto em raros casos individuais, mostra-se permeável a conviver com a diferença (BONNICI, 2009, p. 82). Assim, em temas como o Apartheid na literatura, por exemplo, não se observa a transculturação, isto é, a troca cultural. Todavia, a literatura africana em língua inglesa pode, sim, contribuir para a exposição da marginalização que os brancos praticam contra os negros; ainda que isso não seja considerado uma solução, é de grande importância para que a identidade cultural dos negros não se perca ao longo da história.

Provando que essa solução ainda esteja longe de acontecer, Telles (2003, p. 324) afirma que o movimento negro, por si só, não tem a força de um movimento de massa que possa, de modo eficaz, clamar por mudanças sociais significativas. Se somente os negros, vítimas do racismo, praticarem tais manifestações, ainda assim não é o bastante para que sejam recuperados seus direitos, sobretudo por tudo o que aconteceu ao longo da história, das marcas deixadas de gerações para gerações, pois cada vez mais as dificuldades dessa classificação de "negros" e os sofrimentos por um mundo igualitário já estão enraizadas na população sofrida e percebe-se que há um tipo de anestesia no sentimento de luta por seus direitos.

Por fim, sabe-se que uma democracia racial não será alcançada, pois o planeta não é e nem será uniforme para todos. Pode-se 
dizer que o que de fato pode ser conseguido é um respeito entre as etnias, todavia somente quando a questão do racismo for abordada de forma séria por todos, independente da "cor dérmica"; não deixando o preconceito para quem já é alvo dele.

Racismo E APARTHEID EM DeATH OF a Son (a Morte de um FILHO), DE Njabulo Ndebele.

Filho de Nimrod Njabulo Ndebele e Makhosazana Regina Tshabangu, Njabulo Simakahle Ndebele nasceu em 4 de julho de 1948, em Johanesburgo, na África do Sul. Graduou-se em Língua e Literatura Inglesa e Filosofia pela University of Botswana, Lesotho, and Swaziland, em 1973. Fez seu mestrado em Literatura Inglesa pela Universidade de Cambridge, em 1975, e seu doutorado em 1983, em Filosofia. Njabulo Ndebele foi reitor da Universidade da Cidade do Cabo e Universidade de Limpopo, além de ter ocupado várias outras posições importantes em universidades e fundações por toda a África do Sul (RAMRAJ, 2009, p. 375).

Como escritor, destacou-se com o romance The Cry of Winnie Mandela, recebendo seu livro de contos Fools and Other Stories o prêmio Noma, o mais alto prêmio literário africano. Ndebele também é conhecido por seus ensaios e críticas culturais, tendo a África como leitmotiv.

Por sua forte influência no mundo acadêmico e literário, Njabulo Ndebele aproveitou a literatura como instrumento de denúncia contra as mazelas da colonização e a perversa segregação racial que ainda assombra a África do Sul, como em seu conto Death of a son, publicado em 1996.
É importante saber o significado do que é colonialismo, para que se entenda mais claramente o que são os estudos pós-coloniais e o que nos diz e denuncia a literatura pós-colonial. Colonialismo é o termo que se refere à política de exercer o controle ou a autoridade sobre um território ocupado e administrado por um grupo de indivíduos por meio militar ou político (PARADISO, BARZOTTO, 2007 p. 125). Sendo a colonização um processo de invasão, é apropriado lembrar que geralmente é contra a vontade do colonizado, havendo uma opressão militar, econômica e cultural sobre o povo colonizado. Entender o que esse colonialismo impõe ajuda a entender o valor dos termos pós-coloniais e da literatura também pós-colonial. Ademais, os estudos pós-coloniais analisam as consequências da colonização na cultura. A partir disso, temos na literatura pós-colonial os relatos de toda a cultura afetada pelo império desde o momento da colonização até hoje. Devemos saber que o imperialismo é uma ideia do colonialismo, com poder econômico tendo concentração no capital e nos monopólios.

$\mathrm{Na}$ África do Sul essa invasão e o regime Apartheid desencadearam uma grande perda de identidade.

A colonização europeia, ao apropriar-se das terras dos nativos africanos, desencadeou enorme desorganização na economia do continente, obrigando os povos locais a abandonarem a agricultura, a pesca, a caça ou até mesmo a produção metalúrgica - que algumas sociedades dominavam muito bem -, para atender às exigências dos colonizadores. (PENNAFORTE, 2006, p. 19). 
Sendo assim, o processo de colonização e dominação de uma minoria branca sobre a maioria negra provocou grandes alterações culturais na África do Sul. Foi preciso vestir-se e se comportar como os europeus queriam, deixar a vida "selvagem" que levavam para que se justificasse o que eles chamavam de civilização, segundo a mentalidade eurocêntrica.

Com a independência o aparelho do Estado ficou nas mãos de uma elite educada segundo os padrões ocidentais. Esses dirigentes tinham um discurso anticolonialista, mas na prática suas medidas evitavam mudanças sociais profundas. Para eles, as mudanças poderiam provocar conflitos e colocar em risco a unidade que precisava ser mantida a todo o custo para atender seus interesses. (FIGUEIRA, 2002, p. 363).

Esta literatura mostra a relação entre colonizador e colonizado, centro e margem. No conto Death of a son será visto o contexto da cultura vivida na África do Sul e como a opressão militar dos colonizadores brancos e por policiais, que também eram brancos, afetou a vida do casal em questão.

O pós-colonialismo compreende toda a cultura influenciada pelo processo imperial desde o início da colonização até a contemporaneidade. Independente de suas características especificamente regionais, a literatura pós-colonial é o resultado da experiência de colonização baseada na tensão com o poder colonizador. (ASHCROTF; GRIFFITHS; TIFFIN, 1991, p. 3).
E é dessa tensão entre colonizador branco e colonizado negro que nós encontramos uma literatura carregada de artefatos para o revide, ou seja, é uma forma de reverter o binarismo e abalar as ordens impostas pelo poder colonial, que se postou como centro (BONNICI, 2009, p. 217). O conteúdo desta literatura é uma forma linguística de revide do colonizado, de se colocar a par da situação e de mostrar que ele sabe da sua história e do que aconteceu no seu país, de denunciar toda a carga negativa que o poder "eurocêntrico" determinou sobre o povo colonizado e das marcas que ficaram cravadas na sua cultura, na sociedade e, sobretudo, no olhar daquele que despreza a história do sujeito negro, revelando um olhar inerte a esses acontecimentos históricos.

Neste contexto histórico pós-colonial e carregado de significados, temos o conto Death of a son de Njabulo Ndebele, que relata a história de um casal de sul-africanos: Buntu, o esposo, e a narradora, esposa dele, que não revela seu nome. Em meio aos preconceitos e a opressão, eles tentam incessantemente recuperar o corpo de seu filho, que foi morto por policiais brancos. Este conto mostra a distinção marcada que perdura entre brancos e negros, mesmo após cessado o regime de segregação racial. Isto é claramente identificado no tratamento que os brancos, os policiais, ou seja, os que dominavam, tinham sobre os que não eram considerados gente, pois os policiais brancos os oprimiam duplamente: primeiro, porque eram brancos e se julgavam superiores pela sua cor, e, segundo, porque, por serem 
policiais, se achavam donos das leis, tendo eles assim o direito de serem racistas e não precisar pagar por isso.

No início do conto é mostrada a realidade de um casal no começo do namoro, que via de longe a opressão sobre o seu povo. Eles viam de longe porque, apesar de já ter sido finalizado o regime de segregação racial, não significava que os brancos tratassem os negros por igual, ou seja, em lei já havia acabado, porém, essa linha de divisão racial ainda existia. A humilhação física e psicológica perdurava, pois o olhar, o tratamento dos brancos para com os negros era de quem ainda vivia em regime de segregação racial. Viam, porém, não podiam fazer nada, pois também não tinham voz contra os brancos; suas palavras ficavam apenas presas na garganta e na vontade de assumir o posto de sujeitos da história, então apenas agarravam-se um ao outro, na esperança de tomar para si as suas dores. O mundo hostil em que viviam não deixava que se pudessem fazer promessas e então as palavras já não tinham poder. E é justamente por apoiar-se um no outro que acontece o matrimônio.

Já casados, Buntu trabalha como funcionário de uma fábrica americana de produtos agrícolas, e a esposa, como jornalista. Observa-se que quando se fala que os personagens negros tinham seu emprego, seu posto, significa que eles tinham agência, ou seja, capacidade de agir sobre suas vidas, tomar suas decisões. Dessa união cresce a vontade de comprar coisas, de ter uma vida digna, pacata, capaz de fazer as marcas da sofreguidão serem amenizadas. Nasce uma criança, um menino, a alegria do casal.
Buntu sonhava este menino com um futuro promissor, estudando nas melhores escolas particulares e frequentadas por brancos. Sonhos de um pai que, apesar de carregar na sua pele a tatuagem do regime Apartheid, queria o melhor, uma igualdade, para o filho. "Buntu já havia começado a se informar em escolas particulares de brancos. Era para lá que queria mandar seu filho, que portava seu nome." (NDEBELE, 2007, p.224). Essa tentativa de igualdade advinha da parte da maioria negra, pois eles, sim, tentavam um mundo igualitário. Eles achavam que com o fim do Apartheid todos poderiam ter as mesmas oportunidades, ser tratados por igual; todavia, eles estavam errados em pensar dessa forma, pois em uma sociedade onde os brancos ditam as regras, a igualdade nunca será atingida. Até hoje o mundo não é homogêneo, pois o racismo e o conceito de raça estão enraizados no pensamento social.

Como os pais trabalhavam o dia todo para garantir o sustento da família, a criança ficava com a avó, mãe da narradora. E em um dia de infortúnio, os policiais, brancos, em seus Casspirs ${ }^{1}$, saíram pelas ruas daquele bairro atirando a esmo, distribuindo granadas de gás lacrimogêneo pelas casas; um dos tiros acertou a janela do casal e, infelizmente, o menino. $O$ trecho a seguir ilustra a cena em que a narradora chega a sua casa e descobre a morte da criança.

Era tarde quando voltei para casa e, ao chegar lá, encontrei uma multidão

\footnotetext{
${ }^{1}$ O Casspir é um veículo blindado antiminas, preparado para o transporte de pessoas. Foi usado por toda África do Sul, durante mais de duas décadas.
} 
de gente no jardim. Eram os que não tinham conseguido entrar. Senti pânico. O que havia acontecido? Não perguntei aos que estavam fora, desesperada para entrar em casa. Eles abriram caminho com facilidade quando me reconheceram. Então ouvi a voz de minha mãe. O grito dela subiu bem acima do barulho. Transformouse num berro quando me viu. 'O que foi mãe?', perguntei, abraçando-a com uma sensação de terror vagamente desesperadora. Mas ela me empurrou com uma violência histérica que me chocou. (NDEBELE, 2007, p. 221).

Logo que a narradora começa a ligar as peças daquela cena, a angústia, os sons do choro das pessoas que estavam em volta fizeram com que ela visse a cena em sua mente. Ela era jornalista, portanto cobria cenas violentas envolvendo a polícia, os tiroteios e já imaginava tudo o que não poderia ter sido visto por ela. Mas ela não teve muito tempo para raciocinar sobre o acontecido. A polícia estava passando em mais uma ronda de tiroteios e viu a multidão reunida. Logo entraram na casa, perguntaram sobre o acontecido e como tinha acontecido e em seguida saíram arrastando a mãe da narradora para fora, obrigando-a a não contar o que tinha visto, e levaram o corpo da criança embora. "Por qual estranha lógica esperavam eles que com esse ato a sua carnificina nunca fosse descoberta?" (NDEBELE, 2007, p. 222).

A partir da morte da criança, começa a luta para recuperar seu corpo. A polícia precisa ser protegida e os pais precisam pagar para poder recuperar o corpo de seu filho e enterrá-lo com o devido respeito. Mas as lutas não são de horas e, sim, de dias, de intermináveis dias, de labuta, de humilhação, de condições e promessas falsas e, acima disso, de desrespeito com aquele que é designado "negro".

No final, Buntu consegue recuperar o corpo da criança, depois de muita humilhação; faz o funeral do filho e tenta obter forças, depois da perda, para recomeçar tudo de novo.

O conto em análise retrata as marcas de opressão militar, econômica e cultural que o colonialismo deixou com a invasão europeia da África do Sul. BONNICI (2009, p. 22) diz que a carga de alteridade e objetificação produzida no sujeito colonizado e em toda a sua cultura foi tão devastadora e abrangente que contaminou, em diferente grau e profundidade, a cultura de todos os sujeitos no período pós-independência. Tantos os sujeitos brancos como os negros foram criados a partir desse regime. Os brancos, porque são produtos de uma cultura imperialista, e os negros, porque, além de serem produtos dessa cultura imperialista, o são sob a forma de objeto. Assim, Ndebele, através de Death of a son, mostra a imagem de um povo sofrido que literalmente carrega na derme as marcas do regime de segregação racial e de toda a alteridade e objetificação que esta política causou. Alteridade, porque o sujeito negro é olhado pelo branco com total diferença, tanto de cor como de status social; isso aconteceu antes e acontece na contemporaneidade. Por mais que já tenha acontecido a abolição da escravatura no Brasil em 13 de maio de 1888 e o fim da 
segregação racial na África do sul em 27 de abril 1994, não se pode negar que o sujeito negro é um sujeito diaspórico, ou seja, contra sua vontade ou não, foi banido de sua terra, precisou viver em um lugar estranho, foi desprovido da sua cultura, dos seus costumes, do seu lar.

"O bôer me empurrou para o lado como se estivesse limpando a passagem para sua família" (NDEBELE, 2007, p. 220). Desde o início, com a chegada dos holandeses e ingleses naquela terra, os negros foram empurrados, tirados, privados dos seus costumes, do seu lar, para que os brancos, em sua minoria, passassem e ali estabelecessem o seu forte e olhassem de cima para baixo para os que habitavam aquela terra e ali fundissem a sua cultura conforme sua autoridade permitisse.

Ele - o sujeito negro - é carregado de significados, todavia a história deste sujeito não é levada em consideração; de forma negativa, ele é olhado com diferença, discriminado e alvo do racismo. E é nessa trama pós-colonial que se verifica a forte presença do racismo e do regime do Apartheid. Pode-se dizer que o termo raça cause muita discussão hoje, principalmente no período de globalização, o que não quer dizer que isso tenha começado somente agora. Desde o início do período colonial, a classificação por grupos distintos começou a dar forma para o termo raça. No fim do século XVII, ou seja, no auge do crescimento do comércio colonial, os grupos humanos não eram apenas distintos por características faciais e cor da pele, mas especialmente hierarquizados em categorias superiores (brancos) e inferiores (negros) (BONNICI, 2005, p. 50).
Sob esse ângulo, verifica-se que os povos das raças consideradas não europeias foram intitulados primitivos e inseridos na área marginal e de subordinados, seguindo o sistema de que as raças não europeias deveriam assumir a condição de margem e o europeu, imperial, no centro, criando uma ideologia de superioridade racial. Todavia, por mais que não se queira falar sobre teorias raciais, BONNICI (2005) endossa que há um consenso entre os antropólogos e geneticistas de que a classificação morfológica dos humanos significa muito pouco em termos de genoma, embora a aparência física seja socialmente salientada. Atualmente, a aparência de uma pessoa faz com que uma sociedade inteira a classifique como sendo de outro grupo sócio-étnico; sendo assim, seu status depende da sua categoria racial.

Esse conto denuncia que o que acontecia na época do regime de segregação racial, acontece depois dela, pois o sujeito negro veio carregado de história, de marcas e, partindo do pressuposto que raça é uma ideia e está enraizada na cabeça as pessoas, pode-se concluir que o preconceito racial também está. O termo raça emprega-se de forma pejorativa, pois, desde o século XVII, aqueles que eram designados não europeus eram considerados "raças primitivas" e na hierarquização estavam em último lugar. Raça serve para demarcar ainda mais o binarismo e, mesmo que as ideias raciais desapareçam, o termo ainda será causa de inúmeros debates. É válido, pois, dizer que o termo etnia seria mais adequado e mais humano quando se trata da diversidade dos povos. 
Segundo Telles (2003, p. 301), raça é uma ideia e não um fato biológico. É essa ideia que gera o racismo, o preconceito exacerbado e sem nexo, em relação a uma pessoa designada "de cor". Mesmo que o pensamento de superioridade branca já tenha sido desacreditado, a sociedade mantém as categorias raciais firmadas em suas mentes. Sendo assim, um combinado de atos preconceituosos como outremização, alteridade e racismo fazem do sujeito não branco alvo de humilhações, agressões, piadas, entre outros atos deploráveis.

Entende-se por outremização colocar o sujeito como Outro: a pessoa branca, o colonizador, aquele que faz, que determina, que é sujeito da sua história, exatamente com letra maiúscula para designar pessoa de autoridade, de poder. E como outro: aquele que é designado objeto, o colonizado, o que nada diz, que não tem agência, ou seja, é incapaz de agir na sua própria história, e é colocado com letra minúscula, justamente para mostrar sua condição de menor, de inferior. Bonnici explica o processo de outremização da seguinte forma:

Nesse sentido, vimos que quando o colonizador se posiciona como Outro e superior, centro, sujeito, relegando o outro, colonizado, à margem, à inferioridade, à condição de objeto, o processo de outremização se completa e o sujeito colonial passa a ter seus valores, sua cultura, suas práticas negadas e relegadas à condição de ilegítimas perante os olhos europeus. (BONNICI, 2009, p. 245).

Para ilustrar o racismo no conto de Ndebele, apontamos o fato de uma das hu- milhações provenientes do preconceito racial - a condição de o casal ter de pagar pelo corpo de seu único filho:

[...] durante duas semanas inteiras, todos os esforços de Buntu, junto com seus amigos, parentes, advogados e os jornais, foram no sentido de garantir a liberação do corpo de meu filho sem a humilhação de te que pagar por ele. (NDEBELE, 2007, p. 217).

Mais adiante, o autor, pela voz da narradora, coloca atos de agressão dos brancos contra o sujeito negro:

Naquele momento, dois rapazes brancos que vinham em nossa direção contrária correram para cima das meninas e sem aviso um deles chutou o pacote de peixe e fritas da mão da menina que o segurava. O segundo rapaz chutou o que restava do pacote. A menina se levantou, sacudindo a mão como se quisesse se livrar da dor. Enquanto isso, os dois meninos seguiram seu caminho, rindo. (NDEBELE, 2007, p. 218).

Outra marca importante no conto em análise é do regime Apartheid, ou seja, o regime de segregação racial que durou quarenta e dois anos na África do Sul. O termo Apartheid se refere "a uma política racial implantada no país e de acordo com esse regime, a minoria branca, os únicos com direito a voto, detinham todo poder político e econômico no país, enquanto à imensa maioria negra restava a obrigação de obedecer rigorosamente à legislação separatista" (FRANCISCO, 2012, s/p). 
Esse regime privou o negro de habitar na sua própria terra, ter sua própria agricultura, votar, andar livremente pelas suas terras, ascender economicamente, entre outras atrocidades. Figueira (2002) diz que a África do Sul era o país mais rico e desenvolvido do continente e era governado porumaminoria, descendentedeholandeses que colonizaram a região. E como uma minoria branca teria tanto domínio sobre a maioria da população de um país? Com seu discurso elaborado, sua visão de alteridade invadiu o país e determinou o que era "certo e errado" e permitido fazer. Mesmo que o regime de segregação racial tenha acabado e que a democracia tenha chegado à África do Sul em 1994 - ano da eleição de Nelson Mandela - ainda restaram algumas heranças dessa colonização devastadora. Então, o autor e, consequentemente, o conto narram a história real, de forma ficcional, denunciando o que os livros narram de forma mais branda: a violência racial na África do Sul.

Por isso, a literatura também sofreria com essas mudanças, pois, ao mesmo tempo em que os escritores queriam debater as questões do país, sentiam-se pressionados e evitavam essa escrita política; o escritor branco não pode reproduzir a história e a memória do colonizado de maneira efetiva e denunciativa.

Ndebele denuncia essa opressão, sobretudo militar: "Tinha acontecido durante o dia, quando os soldados e a polícia vieram patrulhar a towship com seus Casspirs blindados começaram a atirar a esmo pelas ruas" (NDEBELE, 2007, p. 222). Ndebele narra, através do conto, de forma ficcional, a história real, o que não acontece nos dias atuais. Os livros de história e até mesmo os professores trazem de maneira muito branda o fato da violência racial na África do Sul. $O$ conto é baseado na realidade, afinal, muitas mães sofreram com essa mesma humilhação, opressão e atitude racista dos policiais brancos, todavia, a verdade é omitida pela estética de se mostrar uma sociedade capaz de passar por cima do que já aconteceu, esquecendo-se da real opressão dos brancos sobre os negros na África do Sul.

Em Death of a son, os sonhos do casal são desconstruídos a partir da morte de seu único filho. Buntu tenta ser sujeito da sua própria história, acreditando que após o término do regime Apartheid o mundo poderia ser igualitário e os negros poderiam ter os mesmos direitos, como o de colocar o filho em uma escola onde estudava uma maioria branca, "Buntu já havia começado a se informar em escolas particulares de brancos. Era para lá que queria mandar seu filho, que portava seu nome." (NDEBELE, 2007, p. 224.), ou até mesmo tendo seus próprios empregos:

Buntu, funcionário do departamento de pessoal em uma fábrica americana que manufaturava implementos agrícolas. Ele havia viajado aos Estados Unidos e voltado com a mente incendiada de sonhos. (NDEBELE, 2007, p. 223.).

A supremacia branca impediu que essa subjetificação acontecesse, porque não basta somente ter definido essa 'libertação' em lei; os brancos, com seu olhar "por cima" dos negros, faziam como se a objetificação ainda acontecesse psicologicamente. Após 
a morte, "Buntu partia sempre para suportar a derrota sozinho" (NDEBELE, 2007, p. 223.), ter que negociar para conseguir o corpo de seu próprio filho. Como se não bastasse o sujeito negro perder o espaço no seu próprio país, ele deveria ter o recibo que comprovava a posse, a compra do corpo do filho (produto).

Além disso, o crime mostra que, mesmo que os protagonistas tivessem sua casa, seu emprego, seus móveis, seus filhos, a polícia (símbolo metonímico do branco) se achava no direito de sair "atirando a esmo" pelas casas, matando quem quer que fosse, além de cobrar dinheiro para devolver o que já era de direito do sujeito negro, confirmando a injustiça, a ideia de superioridade racial e a corrupção política do regime.

Nota-se que, no conto, a narradora e seu esposo não têm condições de serem sujeitos da história, pois são tratados como objetos (incapacidade de agir); são privados de realizar seus sonhos e, ainda mais, privados por vários dias de realizar o funeral de seu filho. Eles deixam de ter domínio sobre sua história, pois os policiais brancos mostram que quem domina aquela situação são eles: primeiro, por serem brancos; segundo, por serem donos das leis, policiais. O fato de o filho deles ser comercializado revela o ápice da objetificação, pois mostra uma situação de repressão, como se eles ainda não estivessem libertos da segregação racial. Porque eles são negros, porque já foram a maioria dominada pela minoria branca, sofrem como fator de humilhação ter de pagar pelo corpo de seu filho e encobrir a sujeira dos policiais brancos. Isso mostra como a supremacia branca influía no lado humano dos negros, pois, se partirmos do pressuposto que animais não fazem funerais, estariam eles dando o mesmo tratamento para Buntu e sua esposa. Embora conseguissem o corpo de volta, após quase duas semanas, as marcas da sua história ficaram para sempre.

Por fim conseguimos o corpo. Quartafeira. Tempo justo para um enterro no sábado. Estávamos exaustos. Vazios. Com o enterro ainda pela frente. Tínhamos que encontrar a força de sofrer. Não tinha havido tempo para sofrer, realmente. Só muita perplexidade e confusão. Agora sofrer. Pois sofrer não é a consciência da perda? (NDEBELE, 2007, p. 215).

Enfim, a narradora apenas se anestesia e se conforma com toda a situação, tentando recomeçar sua história, não com um final feliz, mas realista.

Eu estaria pronta para mais um mês. Pronta como sempre, a cada e todo mês, para novos começos. E Buntu? Vou ficar com ele agora. Para sempre. Sem sabermos, todos os duros acontecimentos tinham preparado para nós novos começos. Então não vamos resistir? (NDEBELE, 2007, p. 228).

Ndebele, através da narradora do seu conto, questiona sobre o que fazer. No regime de Apartheid, na ideologia racista, na colonização, lutar muitas vezes é em vão; logo, cabe apenas resistir. 


\section{CONSIDERAÇÕES FINAIS}

Não é de se espantar se o negro se sentir anestesiado, sem forças para lutar por seus direitos. O mundo de hoje continua hostil demais, mesmo que de maneira subjetiva, e não é igualitário quando se trata de minorias, como os negros, por exemplo.

Apesar dos avanços sobre igualdade racial, ainda há o racismo velado, ainda existem professores que mostram somente o lado escravo do negro, existem as piadas racistas, existem livros didáticos com algum texto onde o personagem ladrão, o pobre, o marginal é sempre negro; nas novelas atuais, geralmente o assassino ou o sequestrador é um negro. Um mundo igualitário se torna uma realidade utópica, pois, como já foi mencionado no artigo, a ideia de raça está enraizada na mente da sociedade preconceituosa, machista e racista.

As perdas culturais, como a inibição das suas tradições, de sua religião, de sua língua e sociais, assim como a privação do seu desenvolvimento econômico, sua participação na política, não hão de ser recuperados pois tudo já foi vivido e já está registrado, de geração para geração. O branco não vai sentir o que isso significa, por mais que tente se colocar na situação do sujeito negro e saiba da humilhação que foi o regime da segregação racial.

Nas escolas, o termo Apartheid é trabalhado de forma muito mais branda do que realmente deveria ser tratado; o aluno, desde o princípio, passa despercebido sobre questões importantes de fatos realmente relevantes para nossa história; os outros termos, como outremização, alteridade, subjetificação, diáspora, não são conheci- dos. Uma literatura de base sólida, como a africana, não é mostrada nem revelada no âmbito escolar, que é onde acontece tanto preconceito: de raça, de credo, de opção sexual e de gênero.

O presente projeto objetiva revelar as grandes perdas que a nossa sociedade tem em não conhecer a verdadeira história, denunciar a discriminação através desta literatura, pois, se o racismo está longe de acabar, a ideia de racismo que perdura por tantos anos também, visto que está cravada na mente fechada e truncada do ser humano. Se um mundo igualitário ainda está longe de surgir, que seja ao menos um mundo inteligente, ciente da verdade, disposto a aceitar a cultura do próximo num mundo mais humano, capaz de repensar as relações de etnia, as diferentes culturas e alcançar a verdadeira democracia racial, pensando nela de forma coerente e séria.

Por fim, o projeto literário pós-colonial de Njabulo Ndebele vem trazer a voz daqueles que por anos foram silenciados pelas consequências da colonização, aqui, em especial, o regime de Apartheid, denunciando assim uma verdade incontestável sob o viés do luto de uma família, estrangeira em sua própria terra.

\section{REFERÊNCIAS}

ASHCROFT, B., GRIFFITHS, G., TIFFIN, $H$. The empire writes back: theory and practice in post colonial literatures. London: Routledge, 1991.

BONNICI, T. Resistência e intervenção nas literaturas pós-coloniais. Maringá: Eduem, 2009. 
. Conceitos-chave da teoria pós-

colonial. Maringá: Eduem, 2005. Coleção Fundamentum.

CARCHIDI, V. Njabulo Ndebele biography. Disponivel em: <http://biography.jrank. org/pages/4627/Ndebele-Nimrod-Njabulo-Simakahle.html>. Acesso em: 26 março 2011.

FIGUEIRA, D. G. História: novo ensino médio. 1.ed. 7. impres. São Paulo: Ática, 2002.

FRANCISCO, W. C. Apartheid. In:

Brasil escola. Disponível em: <http://www. brasilescola.com/geografia/apartheid.htm> Acesso em: 20 janeiro 2012.

NDEBELE, N. Morte de um filho. In: GORDIMER, N. (Org.). Contando histórias. São Paulo: Companhia das Letras, 2007.

PARADISO, S. R; BARZOTTO, L. A. A teoria, a literatura e a estética do pós-colonialismo. Diálogos e Saberes, v.3, n.1. Mandaguari: Faculdade de Filosofia, Ciências e Letras de Mandaguari, 2007.

PAZZINATO, A. L; SENISE, M. H. V. História moderna e contemporânea. São Paulo: Ática, 1997.

PENNAFORTE, C. África: horizontes e desafios no século XXI. São Paulo: Atual, 2006. RAMRAJ, V. J. Concert of voices: an anthology of world writing in english. 2.ed. Province of Ontario: Broad View Press, 2009.

TELLES, E. Racismo à brasileira. Rio de Janeiro: Relume Dumará, 2003.

Recebido para publicação em 27 jun. 2012. Aceito para publicação em 16 mar. 2012. 